AperTO - Archivio Istituzionale Open Access dell'Università di Torino

\title{
A Brazilian Investigation of the 36-and 16-Item Difficulties in Emotion Regulation Scales
}

\section{This is a pre print version of the following article:}

Original Citation:

Availability:

This version is available http://hdl.handle.net/2318/1617714

since 2017-05-17T17:49:47Z

Published version:

DOI:10.1002/jclp.22404

Terms of use:

Open Access

Anyone can freely access the full text of works made available as "Open Access". Works made available under a Creative Commons license can be used according to the terms and conditions of said license. Use of all other works requires consent of the right holder (author or publisher) if not exempted from copyright protection by the applicable law. 


\begin{tabular}{|l|l|l|l|l|}
\hline$A P T \wedge R A$ & JCLP & jclp22404 & Dispatch: September 29, 2016 & CE: \\
\cline { 2 - 5 } & Journal & MSP No. & No. of pages: 14 & PE: XXXXX \\
\hline
\end{tabular}

\title{
A Brazilian Investigation of the 36- and 16-Item Difficulties in Emotion Regulation Scales
}

\author{
Fabiano Koich Miguel, ${ }^{1}$ Luciano Giromini, ${ }^{2}$ Maíra Stivaleti Colombarolli, ${ }^{2}$ \\ Ana Carolina Zuanazzi, ${ }^{3}$ and Alessandro Zennaro ${ }^{2}$
}

${ }^{1}$ State University of Londrina

${ }^{2}$ University of Turin

${ }^{3}$ University of São Paulo

Objective: About 10 years ago, Gratz and Roemer (2004) introduced the Difficulties in Emotion Regulation Scale (DERS), a 36-item self-report instrument measuring 6 areas of emotion regulation problems. Recently, Bjureberg et al. (2015) have introduced a new, briefer version of the DERS comprising only 16 of the 36 items included in the original version. Because no studies have yet crossvalidated the recently introduced 16-item DERS and the 36-item DERS has never been tested in Brazil, we sought to inspect the psychometric properties of scores from both DERS versions with a nonclinical Brazilian sample. Method: Participants were 725 adult volunteers aged 18-70 years (mean $=30.54$, standard deviation $=10.59$ ), $82.3 \%$ of whom were women. All were administered the DERS along with a number of other self-report and performance-based instruments. Data analyses inspected internal consistency, factor structure, and convergent as well as divergent validity of scores from both DERS versions. Results: Results show that scores from both DERS versions possess good psychometric properties. Interestingly, both versions correlated, in the expected direction, with psychopathology and showed no significant correlations with cognitive measures. Like in other studies, however, the Awareness factor of the 36-item DERS did not produce optimal validity and reliability indexes. Conclusion: Taken together, our findings indicate that the 16-item DERS may be preferred over the 36-item version and provide additional support to the differentiation between emotion regulation and cognitive tasks of emotional perception and abstract and verbal reasoning. (C) 2016 Wiley Periodicals, Inc. J. Clin. Psychol. 00:1-14, 2016.

Keywords: emotion regulation; DERS; Brazil; validity; reliability

The ability to regulate emotions is central to both interpersonal relationships and mental health. In fact, difficulties in emotion regulation (ER) characterize both psychopathological conditions such as borderline personality disorder, depression, or anxiety (Glenn \& Klonsky, 2009; Gross \& Muñoz, 1995; McLaughlin, Mennin, \& Farach, 2007; Mennin, Heimberg, Turk, \& Fresco, 2005); and maladaptive behaviors such as self-injury, alcoholism, or substance abuse (Fox, Axelrod, Paliwal, Sleeper, \& Sinha, 2007; Fox, Hong, \& Sinha, 2008; Gratz, Bornovalova, Delany-Brumsey, Nick, \& Lejuez, 2007; Klonsky, 2009). Furthermore, ER is also important to maternal sensitivity (e.g., de Campora, Giromini, Larciprete, Li Volsi, \& Zavattini, 2014; de Campora, Larciprete, Delogu, Meldolesi, \& Giromini, 2016), well-being (e.g., Nyklíček, Vingerhoets, \& Zeelenberg, 2011), interpersonal relationships (e.g., Giromini, Brusadelli, Di Noto, Grasso, \& Lang, 2015) and, more broadly, health (e.g., Consoli et al., 2006; Freire \& Tavares, 2011; Kossakowska, Cieścińska, Jaszewska, \& Placek, 2010; Willemsen, Haentjens, Roseeuw, \& Vanderlinden, 2009).

Though many definitions of ER have been proposed, it is commonly accepted that ER processes include both the conscious and the unconscious attempts individuals make to influence

We declare that there are no conflicts of interest.

Please address correspondence to: Luciano Giromini, PhD, Department of Psychology, University of Turin, Italy. E-mail: luciano.giromini@unito.it 
the emotions they feel and the way they express them. According to Gross and Thompson (2007), ER in particular may occur via five major strategies: situation selection, situation modification, attentional deployment, cognitive change, and response modulation. That is, emotions may be regulated by preventing and/or avoiding potential stressors, attributing different meanings to ongoing events or situations, and/or modulating the extent to which a given emotion may be acknowledged, experienced, and expressed.

A little more than 10 years ago, Gratz and Roemer (2004) introduced the Difficulties in Emotion Regulation Scale (DERS), a 36-item self-report instrument measuring six areas of ER difficulties: (a) accepting one's own emotions (Nonacceptance), (b) possessing an awareness of one's own emotions (Awareness), (c) having access to ER strategies (Strategies), (d) being able to engage in goal-directed behavior when emotionally aroused (Goals), (e) being able to control one's own impulses (Impulse), and (f) having a clear understanding of one's own emotions (Clarity).

During the past few years, the DERS scores have been widely investigated internationally, demonstrating strong evidence of validity and reliability in various samples and cultural contexts (e.g., Fox et al., 2007; Gratz, 2007; Gratz \& Gunderson, 2006; Gratz, Lacroce, \& Gunderson, 2006; Gratz, Rosenthal, Tull, Lejuez, \& Gunderson, 2006; Gratz, Tull, Baruch, Bornovalova, \& Lejuez, 2008; Salters-Pedneault, Roemer, Tull, Rucker, \& Mennin, 2006; Tull \& Roemer, 2007). However, one of the DERS subscales, Awareness, has been criticized for its validity and reliability being lower than the other five subscales, so that some authors have suggested Awareness to be excluded from the DERS (Bardeen, Fergus, \& Orcutt, 2012). Furthermore, Bjureberg et al. (2015) recently introduced a briefer version of the DERS comprising only 16 of the original 36 items. The new 16-item DERS includes all subscales of the original DERS, except for Awareness, which has been removed, consistent with Bardeen et al. (2012).

\section{The Current Study}

As noted above, the DERS has been investigated in several international samples. For example, Italian (Giromini, Velotti, de Campora, Bonalume, \& Zavattini, 2012), Turkish (Ruganci \& Gençöz, 2010), Spanish (Hervás \& Jódar, 2008), Korean (Cho \& Hong, 2013), Greek (Mitsopoulou, Kafetsios, Karademas, Papastefanakis, \& Simos, 2013), French (Dan-Glauser \& Scherer, 2013), and European Portuguese (Coutinho, Ribeiro, Ferreirinha, \& Dias, 2010) versions have recently been developed and validated. However, to date, no Brazilian versions of the DERS are yet available.

In this respect, it should be noted that there are important differences between European and Brazilian Portuguese. For example, one of the original items of the DERS was "When I'm upset, I take time to figure out what I'm really feeling." The European Portuguese version of this item is "Quando estou em baixo, dedico algum tempo a perceber aquilo que realmente estou a sentir." In Brazilian Portuguese, "em baixo" usually states a relative position (under something), so the expression would not convey the actual meaning, which is to be upset; "perceber" is used to describe perception, not the process of figuring something out; and the gerund form "sentindo" is preferred instead the infinitive "a sentir." Thus, as the authors of the Portuguese DERS also noted (Coutinho et al., 2010, p. 156), the available Portuguese version of the DERS may not be used in Brazil without first making some modifications or adjustments.

Perhaps more important, even though ER is an important construct and a relevant topic of study in affective sciences, currently there are very few instruments validated for assessing this construct on general Brazilian population. Gross and John's (2003) Emotion Regulation Questionnaire has been studied in an elderly Brazilian sample (Batistoni, Ordonez, Silva, Nascimento, \& Cachioni, 2013). Bueno (2013) developed an emotional regulation test based on the Stroop task, but the results were not yet satisfactory. No other measures were found for Brazilian context, creating a gap in this field of research in Brazil.

Moreover, it is currently unknown the extent to which Brazilian individuals might tend to use similar versus different ER strategies when compared to other cultural contexts. Because Brazil appears to be more of a collectivistic rather than individualistic culture (Hofstede, 1991; Biaggio, Vikan, \& Camino, 2005), Vikan, Dias, and Nordvik (2009) recently speculated that 
Brazilians might tend to use different ER strategies when compared to individuals from more individualistic countries. However, this hypothesis has been poorly investigated so far, probably also because of the lack of valid ER measures for use with Brazilian populations.

The current study sought to develop a Brazilian Portuguese version of the DERS to (a) promote cross-cultural comparisons of ER, (b) contribute to the study of the DERS' crosscultural adaptability, (c) facilitate research on ER in Brazil, and (d) investigate the psychometric properties of its scores with a Brazilian sample. Furthermore, because no studies have yet crossvalidated the 16-item version of the DERS recently introduced by Bjureberg et al. (2015), we also intended to provide initial, cross-cultural validation of this briefer version.

Considering that emotion dysregulation typically associates with psychopathology, with deficits in the processing of emotions (i.e., alexithymia) and, as such, difficulties understanding emotions displayed by others (i.e., empathy), we anticipated that the DERS would correlate with alexithymia $(+)$, empathy $(-)$, and maladaptive personality traits $(+)$. We also anticipated that the DERS would not correlate with cognitive abilities because previous research has shown that emotion regulation and intelligence tend to be independent and unrelated constructs (Garner \& Waajid, 2012; Mayer, Salovey, \& Caruso, 2012).

\section{Method}

The original version of the DERS was translated into Brazilian Portuguese via the backtranslation method (Brislin, 1980; Geisinger, 2003; van de Vijver, \& Hambleton, 1996). To accomplish that, a bilingual researcher first translated the DERS from English to Brazilian Portuguese. Then, this version was back-translated into English by another bilingual individual that was blind to the original English version. After that, Dr. Gratz, one of the two authors who developed the DERS, revised the back-translated version to search for any inconsistencies. The few inconsistencies pointed out by the author were thus corrected and back-translated again by other two independent researchers, blind to the original and back-translated versions. After that, Dr. Gratz revised this new Brazilian version and considered it to be consistent with the original English instrument.

\section{Participants}

The sample of this study encompassed 725 adult participants aged $18-70$ years $(M=30.54$, $S D=10.59)$, the majority of whom were female $(82.3 \%)$, with males comprising only a small part of the sample (17.7\%). Most of the subjects were enrolled or had completed college education (52.1\% were undergraduated or in graduation courses and $18.6 \%$ were graduated).

\section{Procedure}

Following all required ethical procedures, we posted an advertisement on a popular social media webpage (Facebook), inviting potential participants to volunteer for this study. The invitation did not discriminate gender, ethnicity, or educational level, but it was advertised only for people aged 18 years or older. Interested volunteers clicked on the advertisement link, which displayed an informed consent form detailing the goals and procedures and requesting participation consent. Participants accepted the invitation to participate by creating an individual username for the site, from which they would take the tests. Informed consent was obtained from all participants included in the study. All instruments included in this study were administered in Brazilian Portuguese. Participants were compensated by presenting their results at the end of the tests, calculated in percentiles according to the tests' previous studies.

\section{Measures}

We asked the participants to complete the measures described below. To meet standard ethical requirements and avoid careless responding, participants were informed that they could discontinue their participation at any time and choose which measures they wanted to complete. As such, not all of the participants completed all the instruments. 
DERS (Gratz \& Roemer, 2004). The original version of the DERS includes 36 items assessing six factors of emotional dysregulation: non-acceptance of emotional responses; difficulties in engage in goal-oriented behaviors; difficulties in control impulses; lack of emotional knowledge; restrict access to emotional regulation strategies; and lack of emotional clarity. Respondents rated the frequency with which each item applies to them on a Likert scale varying from 1 (almost never $0-10 \%$ ) to 5 (almost always $91-100 \%$ ). In their original study, Gratz and Roemer (2004) reported that scores from the DERS have good psychometric properties, with alphas ranging from .77 to .93 , and good test-retest stability and construct validity indexes. As noted in the Introduction, various international studies also support the validity and reliability of the scores from the 36-item DERS.

Bjureberg et al. (2015) recently introduced a briefer version of the DERS. This briefer version includes 16 of the 36 original DERS items, and five of the six original DERS subscales (i.e., it does not include Awareness). In Bjureberg et al.'s (2015) study, the scores from the 16-item DERS demonstrated good psychometric properties, which were comparable to those of the scores from the 36-item DERS. To our knowledge, no other studies have yet investigated this briefer 16-item DERS version.

Computerized Test of Primary Emotions Perception (PEP; Miguel \& Primi, 2014). The PEP is a web-based test to assess the ability to perceive basic emotions, which is one of the aspects of emotional intelligence. The test comprised 35 videos of people expressing basic emotions and participants classified which emotion was being shown (joy, love, fear, sadness, surprise, disgust, anger, and curiosity). The test is scored using Rasch model, considering the correct expressions for each of the 35 videos. Because a few videos have more than one emotional expression, the total amount of expressions in the PEP is 49. The Rasch scores were transformed into $\mathrm{z}$ scores based on the test's norms. In our sample, the $\mathrm{z}$ scores ranged from -3.68 to 2.99 . In previous studies, the PEP scores have demonstrated adequate psychometric properties and evidence of validity to assess this aspect of emotional intelligence in Brazilian samples, with Rasch reliability of .68 and 7-month test-retest correlation of .86 (Miguel \& Primi, 2014). In our sample, Rasch reliability was .62.

The Toronto Alexithymia Scale-20 (TAS-20; Bagby, Taylor, \& Parker, 1993). The TAS-20 is a widely used 20-item self-report measure of alexithymia. Wiethaeuper, Abaide Balbinotti, Pelisoli, and Lopes Barbosa (2005) adapted it to Brazilian Portuguese. The TAS-20 assesses three dimensions of alexithymia: Difficulty Identifying Feelings, Difficulty Describing Feelings, and Externally Oriented Thinking. Participants rated these items using a 5-point Likert scale varying from 1 (completely false) to 5 (completely true), with higher scores indicating higher alexithymia. TAS-20 scores have shown good psychometric properties in various international studies, including a Brazilian one (Wiethaueper et al., 2005). In the current study, alphas were .83 for Difficulty Identifying Feelings, .68 for Difficulty Describing Feelings, .51 for Externally Oriented Thinking, and .82 for the Total TAS-20 score.

Questionnaire for Cognitive and Affective Empathy (QCAE; Reniers, Corcoran, Drake, Shryane, \& Völlm, 2011). This 31-item scale measures cognitive and affective aspects of empathy. Participants rated these items by indicating their level of agreement using a 4-point Likert scale ranging from 1 (strongly agree) to 4 (strongly disagree). The scores are summed for each subscale and for the total, with higher scores meaning higher empathy. The QCAE scores have shown good psychometric properties in the original study from Reniers et al. (2011), and thus the QCAE is deemed to be a valid tool for assessing cognitive and affective empathy.

Because no Brazilian versions of the QCAE were available when we began this study, we followed the translation/back-translation procedure and developed a Brazilian version. To do so, we also consulted with Dr. Reniers, one of the developers of the original version of this instrument. In our study, the alpha of the total QCAE score was .82. For the subscales, alphas were .87 for perspective taking, .83 for online simulation, .69 for emotion contagion, .58 for proximal responsivity, and .34 for peripheral responsivity. For the total scores of affective and cognitive empathy, alphas were .68 and .87 , respectively. 
Clinical Dimensional Personality Inventory-2 (IDCP-2; Carvalho \& Primi, 2015). This test, developed in Brazil, is a 210-item scale assessing various personality characteristics related to personality disorders, with items scored from 1 to 4 points. In preview studies, the IDCP scores have shown good psychometric properties with both patient and nonpatient samples (Abela, Carvalho, Cho, \& Yazigi, 2015; Carvalho \& Primi, 2015). The IDCP-2 assesses 12 factors of maladaptive personality aspects, which are listed below, followed by the Cronbach's alpha values obtained in the current study: Dependency (.91), Aggressiveness (.89), Mood instability (.86), Eccentricity (.86), Attention seeking (.80), Distrust (.87), Grandiosity (.86), Isolation (.88), Criticism avoidance (.89), Self-sacrifice (.90), Conscientiousness (.84), and Impulsiveness (.89).

Battery of Reasoning Tests-5 (BPR-5; Primi \& Almeida, 2000). This battery of tests was developed to assess general reasoning and abilities in a Brazilian sample. For this research, we used two subscales-verbal reasoning (VR) and abstract reasoning (AR)-both of which comprise 25 items with analogy. In the first subscale, the participants identify relationships between words, and in the second one, they use reasoning to identify relationships between abstract geometric figures. As for any ability measure, higher scores indicate better performances on the test. In this study, internal consistency was .80 for AR and .66 for VR.

\section{Data Analyses}

Data analyses aimed at inspecting the psychometric properties of the 36- and 16-item DERS scores. Specifically, we tested internal consistency, factor structure, convergent validity, and divergent validity for each of the two DERS versions' scores. To study the validity of the DERS scores, we used Pearson correlations and inspected whether they correlated with other related (convergent validity) or unrelated (divergent validity) psychological constructs.

Because some of the other instruments included in this study contain a large number of factor scores, we chose only relevant variables to be correlated with the DERS. We used the total scores of the TAS-20, PEP, AR, and VR; the QCAE's cognitive empathy and affective empathy scores; and the IDCP-2's Mood instability (mood changes and distressful emotions), Criticism avoidance (doing unpleasant things to satisfy others), Self-sacrifice (avoiding contact with other people so one will not be criticized), and Impulsiveness (aggressive emotions towards other people) scores because we considered them to be closely linked to emotional dysregulation.

\section{Results}

\section{DERS Scores}

Table 1 presents the descriptive statistics of both DERS versions (36- and 16-item) for the entire sample, separated by gender. We found few significant statistical differences between scores produced by men and women. Specifically, women scored higher than men on Nonacceptance (only for the 36-item version) and Impulse (both versions), but the effect size of these differences was small (Cohen, 1988), indicating that there are no notable distinctions between women and men regarding emotional regulation. In fact, when we ran partial correlations controlling for gender to study the convergent and divergent validity of the DERS scores (further ahead), the correlation magnitudes were very similar, with no noteworthy discrepancy between partial correlations and Pearson correlations.

In general, the DERS scores showed significant correlations with age, in the expected direction (i.e., older participants displayed better emotional regulation than younger participants), albeit with low magnitude. The correlation range was -.07 to -.25 .

\section{Internal Consistency}

We calculated Cronbach's alphas and item-total correlations to examine the internal consistency of scores from both versions of the DERS, the results of which are presented in Table 2. For the 36 -item version, Cronbach's alphas ranged from .67 to .91, while for the 16-item version, 


\section{6}

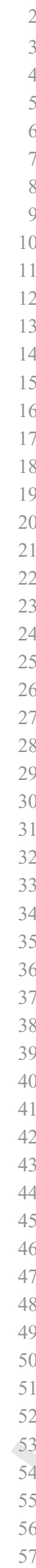

Journal of Clinical Psychology, xxxx 2016

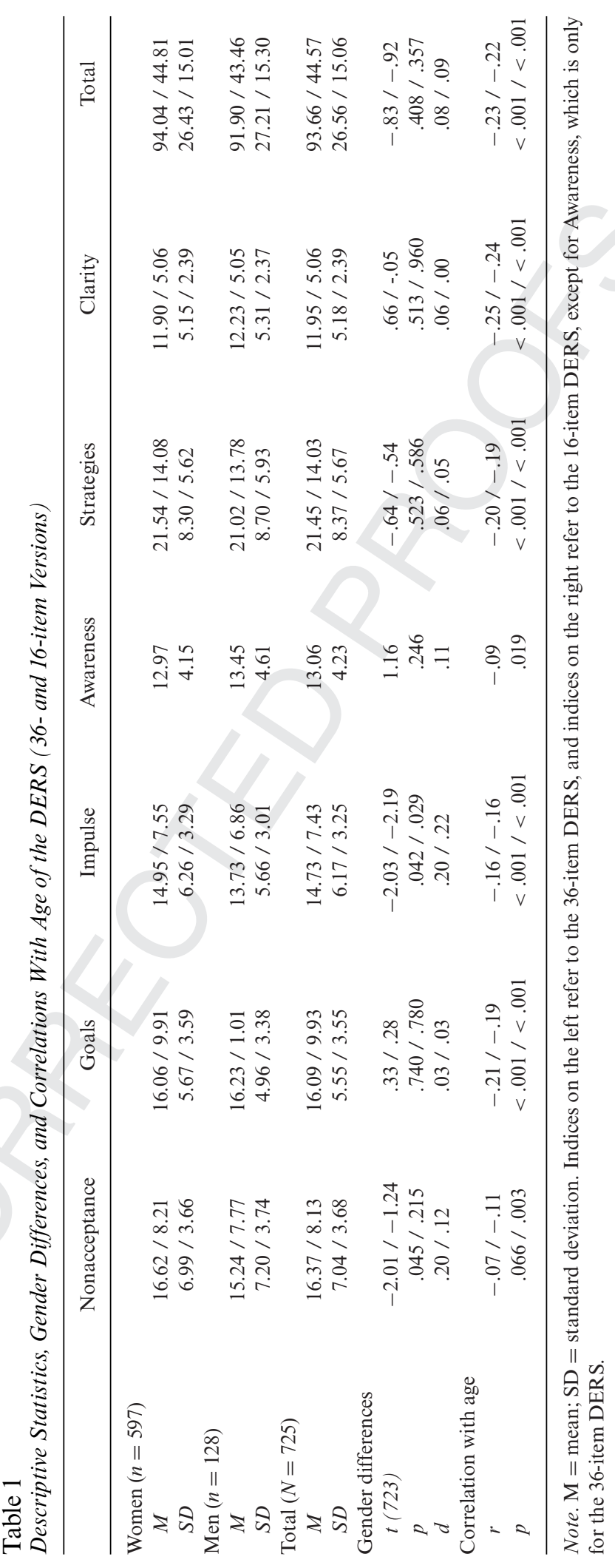


Table 2

Internal Consistency Analyses for the DERS (36- and 16-item Versions)

\begin{tabular}{lccc}
\hline & No. of items & Cronbach's alpha & Range of item-total correlations \\
\hline Nonacceptance & $6 / 3$ & $.90 / .81$ & $.75-.86 / .73-.86$ \\
Goals & $5 / 3$ & $.90 / .86$ & $.73-.90 / .84-.89$ \\
Impulse & $6 / 3$ & $.89 / .80$ & $.65-.88 / .65-.88$ \\
Awareness & 6 & .67 & $.48-.78$ \\
Strategies & $8 / 5$ & $.91 / .87$ & $.63-.86 / .74-.86$ \\
Clarity & $5 / 2$ & $.91 / .82$ & $.83-.89 / .85-.89$ \\
Total & $36 / 16$ & $.94 / .93$ & $-.22-.77 / .56-.77$ \\
\hline
\end{tabular}

Note. Indices on the left refer to the 36-item DERS, and indices on the right refer to the 16-item DERS, except for Awareness, which is only for the 36-item DERS.

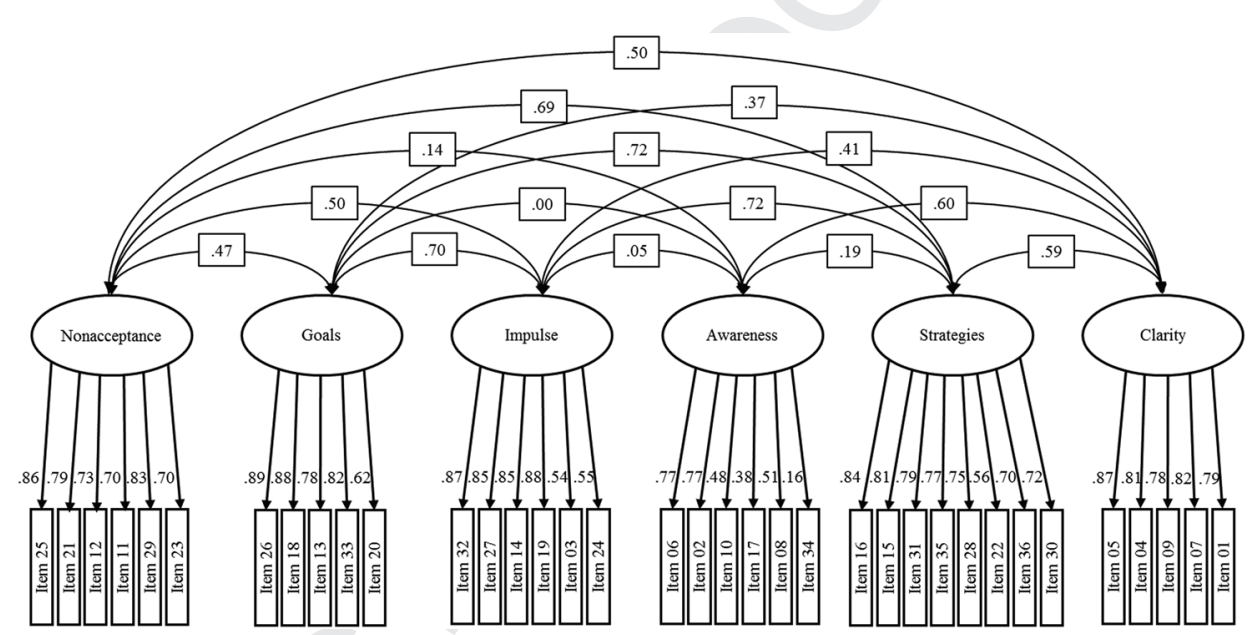

Figure 1. Factor Structure of the 36-item Version of the DERS

the range was from .80 to .87 . Apart from the Awareness subscale of the 36-item DERS, all indices were very good, with excellent consistency for the total scores (i.e., .94 for 36-item DERS and .93 for the 16-item DERS). Our results are very similar to those found in the original scale development studies (Bjureberg et al., 2015; Gratz \& Roemer, 2004), except for Awareness, which produced a lower alpha in our study (i.e., .67) than in Gratz and Roemer's (2004) original study (i.e., .80).

\section{Factor Structure}

We conducted confirmatory factor analyses (CFAs) to evaluate the proposed factor structure of both DERS versions. Factor loadings and correlations are detailed in Figure 1 (36-item) and Figure 2 (16-item). For the 36-item version, the root mean square error of approximation (RMSEA) was .073 (90\% confidence interval [CI] [.071, .076]), non-normed fit index (NNFI) was .96, comparative fit index (CFI) was .97, and standardized root mean residual (RMR) was .085 . For the 16-item version, RMSEA was .096 (90\% CI $[.089, .100])$, NNFI was .96, CFI was .97 , and standardized RMR was .054. Although the RMSEA values indicate a fair or marginal fit (Browne \& Cudeck, 1993), all other indices designate a good fit, especially for the 16-item version (for interpretative benchmarks of CFI and NNFI, see Bentler \& Bonett, 1980; for interpretative benchmarks of standardized RMR, see Hu \& Bentler, 1999).

It should be noted, however, that the Awareness subscale of the 36-item version showed weak associations with all other subscales (below .20), except for Clarity (.60). Furthermore, one of 


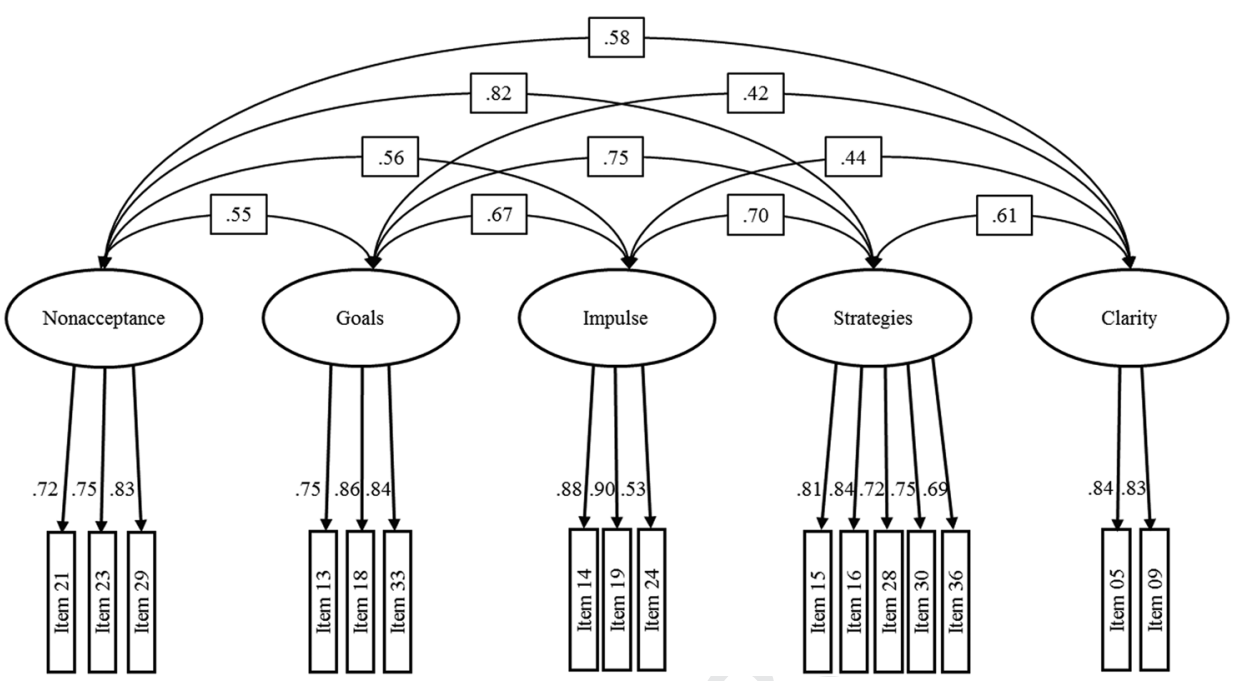

Figure 2. Factor Structure of the 16-item Version of the DERS

Table 3

Correlations of the 36-Item DERS With Alexithymia, Empathy, Maladaptative Personality Traits, and Cognitive Tasks

\begin{tabular}{lccccccc}
\hline & Nonacceptance & Goals & Impulse & Awareness & Strategies & Clarity & Total \\
\hline TAS-20 $(n=725)$ & $.41^{* *}$ & $.33^{* *}$ & $.42^{* *}$ & $.40^{* *}$ & $.51^{* *}$ & $.77^{* *}$ & $.65^{* *}$ \\
QCAE $(n=725)$ & & & & & & & \\
$\quad$ Cognitive empathy & $-.15^{* *}$ & $-.18^{* *}$ & $-.26^{* *}$ & $-.35^{* *}$ & $-.26^{* *}$ & $-.37^{* *}$ & $-.35^{* *}$ \\
$\quad$ Affective empathy & $.26^{* *}$ & $.23^{* *}$ & $.25^{* *}$ & $-.18^{* *}$ & $.25^{* *}$ & $.12^{* *}$ & $.25^{* *}$ \\
IDCP $(n=218)$ & & & & & & & \\
$\quad$ Mood instability & $.45^{* *}$ & $.52^{* *}$ & $.60^{* *}$ & .05 & $.69^{* *}$ & $.45^{* *}$ & $.69^{* *}$ \\
Criticism avoidance & $.40^{* *}$ & $.40^{* *}$ & $.37^{* *}$ & $.16^{*}$ & $.56^{* *}$ & $.43^{* *}$ & $.57^{* *}$ \\
Self-sacrifice & $.47^{* *}$ & $.35^{* *}$ & $.39^{* *}$ & .13 & $.62^{* *}$ & $.47^{* *}$ & $.61^{* *}$ \\
$\quad$ Impulsiveness & .07 & $.24^{* *}$ & $.35^{* *}$ & -.04 & $.21^{* *}$ & $.15^{*}$ & $.25^{* *}$ \\
Emotional perception $(n=725)$ & -.02 & .06 & -.01 & $-.10^{* *}$ & .01 & -.04 & -.01 \\
Verbal reasoning $(n=275)$ & -.06 & .02 & -.10 & -.10 & -.09 & -.07 & -.10 \\
Abstract reasoning $(n=139)$ & -.08 & .12 & -.04 & -.05 & -.01 & .00 & -.02 \\
\hline
\end{tabular}

Note . DERS = Difficulties in Emotion Regulation Scale; TAS-20 = Toronto Alexithymia Scale-20; QCAE = Questionnaire for Cognitive and Affective Empathy; IDCP = Clinical Dimensional Personality Inventory-2. ${ }^{*} p<.05 .{ }^{* *} p<.01$.

the Awareness items (i.e., item 34) had a factor loading of .16, a notably lower value compared to all other factor loadings of the model. Thus, our CFA indicates that Awareness did not fit perfectly with the factor structure proposed by Gratz and Roemer (2004).

\section{Convergent Validity}

Tables 3 and 4 present the correlations of the DERS (36-item and 16-item versions, respectively) with alexithymia, empathy, maladaptive personality traits, and cognitive tasks. The TAS-20 correlations were all significant. These indices tended to be higher for the DERS' Clarity subscale, which was expected because alexithymia implies lack of knowledge of one's own emotions.

Most correlations between the DERS and the QCAE were significant, although with lower magnitude than what was found for the TAS-20. In general, these results showed that difficulties 
Table 4

Correlations of the 16-item DERS With Alexithymia, Empathy, Maladaptative Personality Traits, and Cognitive Tasks

\begin{tabular}{lccccrr}
\hline & Nonacceptance & Goals & Impulse & Strategies & Clarity & Total \\
\hline TAS-20 $(n=725)$ & $.44^{* *}$ & $.34^{* *}$ & $.38^{* *}$ & $.50^{* *}$ & $.72^{* *}$ & $.57^{* *}$ \\
QCAE $(n=725)$ & & & & & & \\
$\quad$ Cognitive empathy & $-.18^{* *}$ & $-.18^{* *}$ & $-.26^{* *}$ & $-.23^{* *}$ & $-.32^{* *}$ & $-.28^{* *}$ \\
$\quad$ Affective empathy & $.25^{* *}$ & $.22^{* *}$ & $.23^{* *}$ & $.27^{* *}$ & $.13^{* *}$ & $.28^{* *}$ \\
IDCP $(n=218)$ & & & & & & \\
$\quad$ Mood instability & $.50^{* *}$ & $.52^{* *}$ & $.51^{* *}$ & $.68^{* *}$ & $.40^{* *}$ & $.68^{* *}$ \\
Criticism avoidance & $.43^{* *}$ & $.41^{* *}$ & $.33^{* *}$ & $.55^{* *}$ & $.33^{* *}$ & $.53^{* *}$ \\
$\quad$ Self-sacrifice & $.51^{* *}$ & $.37^{* *}$ & $.31^{* *}$ & $.62^{* *}$ & $.40^{* *}$ & $.57^{* *}$ \\
$\quad$ Impulsiveness & .11 & $.25^{* *}$ & $.32^{* *}$ & $.23^{* *}$ & .11 & $.26^{* *}$ \\
Emotional perception $(n=725)$ & .01 & .05 & .00 & .01 & -.02 & .01 \\
Verbal reasoning $(n=275)$ & -.06 & -.01 & -.04 & -.10 & -.05 & -.07 \\
Abstract reasoning $(n=139)$ & -.01 & .10 & -.07 & -.02 & .01 & .00 \\
\hline
\end{tabular}

Note . DERS $=$ Difficulties in Emotion Regulation Scale; TAS-20 = Toronto Alexithymia Scale-20; QCAE = Questionnaire for Cognitive and Affective Empathy; IDCP = Clinical Dimensional Personality Inventory-2. ${ }^{*} p<.05 .{ }^{* *} p<.01$.

in ER is negatively related to cognitive empathy ability (i.e., seeing things from other people's perspective and imagining what they are feeling). On the other hand, difficulties in ER showed positive correlations with affective empathy, which is related to responsiveness to other people's emotional states.

Both DERS versions also showed several significant correlations with the factors of IDCP. The most prominent results were that limited regulation strategies correlated to criticism avoidance and self-sacrifice, and impulse control difficulties correlated to mood instability.

\section{Divergent Validity}

To investigate divergent validity, we ran correlation analyses between both DERS versions and a number of cognitive tasks, the results of which are also presented in Tables 3 and 4 . There was only one statistically significant correlation, which was still very low. The results give support to the differentiation of ER from the cognitive tasks of emotional perception and abstract and verbal reasoning.

\section{Discussion}

Measuring emotion dysregulation is crucial to both clinical practice and research in psychopathology, and during the past few years, the DERS (Gratz \& Roemer, 2004) has been widely investigated internationally. Very recently, some authors have also introduced a new, briefer version of the DERS, which comprises only 16 of the 36 items included in the original version (Bjureberg et al., 2015). Because no studies have yet cross-validated the recently introduced 16-item DERS version and the 36-item DERS has never been tested in Brazil, the current study sought to inspect the psychometric properties of scores from both DERS versions with a relatively large sample of nonclinical Brazilian adults. Taken together, the results of our study indicate that the scores of both DERS versions possess adequate psychometric properties, even though the Awareness factor of the 36-item DERS did not produce optimal validity and reliability indexes.

Internal consistency analyses showed that the Nonacceptance, Goals, Impulse, Strategies, and Clarity subscales of both DERS versions had Cronbach's alphas $\geq .80$. Likewise, these subscales produced high item-total correlations $(\geq .63)$ and high factor loadings $(\geq .54)$ in the 
CFA. Conversely, the Awareness factor of the 36-item DERS produced a nonoptimal alpha of .67 (for benchmarks, see Nunnally, 1978) and lower item-total correlations $(\min =.48)$ and factor loadings $(\min =.16)$ compared to the other DERS subscales. In addition, Awareness showed a weak relationship (below .20) with four of the other five DERS subscales, in the CFA. Taken together, these findings are consistent with Bardeen et al. (2012) and thus suggest that Awareness should be used with care in future assessment or research.

We anticipated that the DERS would positively correlate with the TAS-20 and negatively with the QCAE, in that emotion dysregulation typically associates with deficits in the recognition and understanding of one's own emotions (i.e., alexithymia) and understanding of others' feelings (i.e., empathy). These hypotheses were confirmed only partially. Indeed, while the DERS did positively correlate with the TAS- 20 and negatively with the cognitive empathy scales of the QCAE, some positive correlations between the DERS and the affective empathy scales of the QCAE were also found. A possible explanation for this unexpected finding (i.e., the positive correlation between the DERS and affective empathy) could be that both emotion dysregulation and emotion contagion (subcomponents of affective empathy) often associate to psychopathology.

A closer look at the three QCAE subscales measuring affective empathy (i.e., Emotion Contagion, Proximal Responsivity, and Peripheral Responsivity) reveals that Emotion Contagion is the only one that produced medium-sized correlations with the DERS $(-.05 \leq r \leq .41$ for the 36-item version; $.28 \leq r \leq .41$ for the 16 -item version), while the other two subscales only produced correlations of $r \leq .15$, mostly nonsignificant. In fact, the correlations between the DERS total scores and Emotion Contagion were around .40, while the correlations between the total DERS scores and the other two affective empathy subscales were $\leq .11$. Thus, the QCAE's Emotion Contagion subscale likely played a key role in determining the observed positive correlation between DERS and affective empathy. Like emotion dysregulation, emotion contagion also seems to positively associate to psychopathology because it is a proposed risk factor for eating disorders (Weisbuch, Ambady, Slepian, \& Jimerson, 2011) and is positively associated with schizophrenia (Michaels et al., 2014). Though this hypothesis may or may not be true, additional research on this topic would certainly be beneficial.

Both DERS versions showed strong correlations with the IDCP factors, which is consistent with previous research suggesting that personality disorders and other maladaptive conditions are associated with lower ability to regulate emotions (Fox et al., 2007, 2008; Glenn \& Klonsky, 2009; Gratz et al., 2007; Gross \& Muñoz, 1995; Klonsky, 2009; McLaughlin et al., 2007; Mennin et al., 2005). The highest correlations between the DERS total scores and the IDCP factors were Mood instability, Self-sacrifice, and Criticism avoidance. These results show a great overlap between the lack of emotional regulation, rapid mood changes, and experience of distressful emotions; attitude to do unpleasant things to satisfy others; and tendency to avoid contact with other people to avoid criticism.

The correlations between the DERS Impulse and IDCP Impulsiveness, albeit significant, were mild ( .35 for the 36 -item DERS and .32 for the 16-item DERS), and in fact Impulse produced stronger correlations with other subscales of the IDCP. Although this result may seem unexpected, it is important to note that only the labels of these factors are similar. The DERS Impulse measures the difficulty to remain in control while experiencing negative emotions (Gratz \& Roemer, 2004), but the IDCP Impulsiveness is related to the antisocial personality disorder (Carvalho \& Primi, 2015), with items such as "I like to watch violent movies" and "I am very good to make up excuses when I am in trouble." Thus, although the two scales share some variance, most likely explained by the experience of negative emotions reactivity, they do not assess the exact same construct.

Our research also contributes to the understanding of ER by comparing the DERS with cognitive tasks, an analysis that had never been published before. As expected, our results supported that ER and cognitive abilities are independent and unrelated constructs: The correlations between the DERS and the cognitive tasks included in our study were close to null. At a first sight, ER and emotional perception may seem to be related constructs. In line with this hypothesis, a previous study (Jesus \& Noronha, 2007) using the Mayer-Salovey-Caruso Emotional Intelligence Test (MSCEIT; Mayer, Salovey, \& Caruso, 2002) with 191 Brazilian participants found a significant, albeit small (.26), correlation between emotional perception and emotional regulation 
tasks. However, other international studies with the MSCEIT as well as various other measures showed no significant correlations between emotional perception and regulation (Mayer et al., 2012). In line with these international studies, our results also support the hypothesis that ER comprises a different set of skills that are unrelated to emotional perception.

In conclusion, based on the findings of the current study, we believe that scores from both DERS versions possess very good psychometric properties and are highly robust to crosscultural adaptations. All in all, however, we encourage researchers to give particular attention to the 16-item version because it (a) takes less time to complete than the 36-item DERS; does not contain the Awareness subscale, which displayed poor psychometrics in this and other studies; and showed validity and internal consistency indices comparable to the 36 -item version. On the other hand, it should be noted that the 16-item DERS' Clarity subscale is measured by only two items. Although it is not uncommon for psychological measures to include two markers only for a given factor (e.g., Keith, Caemmerer, \& Reynolds, 2016; Weiss, Keith, Zhu, \& Chen, 2013), factors measured by at least three items typically tend to be more valid and reliable (Raubenheimer, 2004).

Considering the relevance of this field of study in recent psychology research and affective sciences, we consider that our validation of the Brazilian DERS provides a secure measure to be used in both clinical and nonclinical samples in Brazil. Specifically, we believe that our findings facilitate research in fields in which emotional dysregulation might be highly implicated such as mental illness (depression, anxiety, personality disorders), health problems like obesity, social adjustment, and other correlated areas.

\section{Limitations}

Some limitations of the study, however, should be kept in mind while reading this article. First, because our data were collected using computerized online procedures, the generalizability of our findings may be questioned, and some of the respondents may have put little effort in completing some of the measures. The fact that all our reliability and validity results were highly consistent with those found by many other, international authors suggests that this concern is unlikely to represent a serious problem. However, additional research with paper-and-pencil data collection would certainly be beneficial. Second, all measures used in this study to test convergent validity were self-reported and thus are subject to social desirability and other biases. Accordingly, it would be useful for future research to cross-validate our findings with performance-based and/or behavioral assessment measures as well. Furthermore, the majority of the sample was female and enrolled or had completed college education, which may limit the generalizability of the study's findings to other populations. Still, the differences between genders were very low or null.

\section{Conclusion}

Despite these (and other) limitations, however, our study is the first to investigate the DERS in Brazil and provide initial cross-cultural validation of the recently introduced 16-item DERS.

All procedures performed in studies involving human participants were in accordance with the ethical standards of the institutional and/or national research committee and with the 1964 Helsinki declaration and its later amendments or comparable ethical standards.

\section{References}

Abela, R. K., Carvalho, L. F., Cho, S. J. M., \& Yazigi, L. (2015). Validity evidences for the Dimensional Clinical Personality Inventory in outpatient psychiatric sample. Paidéia (Ribeirão Preto), 25(61), $221-$ 228. doi:10.1590/1982-43272561201510

Bagby, R. M., Taylor, G. J., \& Parker, J. D. A. (1993). The twenty-item Toronto Alexithymia scale-II: Convergent, discriminant, and concurrent validity. Journal of Psychosomatic Research, 38, 33-40.

Bardeen, J. R., Fergus, T. A., \& Orcutt, H. K. (2012). An examination of the latent structure of the Difficulties in Emotion Regulation Scale. Journal of Psychopathology and Behavioral Assessment, 34(3), 382-392. 
Batistoni, S. S. T., Ordonez, T. N., Silva, T. B. L., Nascimento, P. P. P, \& Cachioni, M. (2013). Emotional Regulation Questionnaire (ERQ): Indicadores psicométricos e relações com medidas afetivas em amostra idosa. Psicologia: Reflexão e Crítica, 26(1), 10-18. doi:10.1590/S0102-79722013000100002

Bentler, P. M., \& Bonett, D. G. (1980). Significance tests and goodness-of-fit in the analysis of covariance structures. Psychological Bulletin, 88, 588-600.

Biaggio, A., Vikan, A., \& Camino, C. (2005) Orientacao social, papel sexual, e julgamento moral: um comparacao de duas amostras Brasileiras e uma Norueguesa. Revista de Psicologia: Reflecao \& Critica, $18,1-6$.

Bjureberg, J., Ljótsson, B., Tull, M. T., Hedman, E., Sahlin, H., Lundh, L. G.. . . \& Gratz, K. L. (2015). Development and Validation of a Brief Version of the Difficulties in Emotion Regulation Scale: The DERS-16. Journal of Psychopathology and Behavioral Assessment, 38, 284. doi:10.1007/s10862-0159514-x

Brislin, R. W. (1980). Translation and content analysis of oral and written material. In H. C. Triandis, \& J. W. Berry (Eds.), Handbook of cross-cultural psychology (Vol.1, pp. 389-444). Boston: Allyn \& Bacon.

Browne, M. W., \& Cudeck, R. (1993). Alternative ways of assessing model fit. In K. A. Bollen \& J. S. Long (Ed.), Testing structural equation models (pp. 136-162). Beverly Hills: Sage.

Bueno, J. M. H. (2013). Construção e validação de um instrumento para avaliação da regulação emocional. Estudos Interdisciplinares em Psicologia, 4(2), 186-200. doi:10.5433/2236-6407.2013v4n2p186

Carvalho, L. F., \& Primi, R. (2015). Development and internal structure investigation of the Dimensional Clinical Personality Inventory. Psicologia: Reflexão e Crítica, 28(2), 322-330. doi:10.1590/16787153.201528212

Cho, Y., \& Hong, S. (2013). The new factor structure of the Korean version of the Difficulties in Emotion Regulation Scale (K-DERS) incorporating method factor. Measurement and Evaluation in Counseling and Development, 46(3), 192-201. doi:10.1177/0748175613484033

Cohen, J. (1988). Statistical power analysis for the behavioral sciences (2nd ed.). Hillsdale, NJ: Erlbaum.

Consoli, S. M., Rolhion, S., Martin, C., Ruel, K., Cambazard, F., Pellet, J., \& Misery, L. (2006). Low levels of emotional awareness predict a better response to dermatological treatment in patients with psoriasis. Dermatology, 212, 128-136.

Coutinho, J., Ribeiro, E., Ferreirinha, R., \& Dias, P. (2010). The Portuguese version of the Difficulties in Emotion Regulation Scale and its relationship with psychopathological symptoms. Revista de Psiquiatria Clínica, 37(4), 145-151.

Dan-Glauser, E. S., \& Scherer, K. R. (2013). The Difficulties in Emotion Regulation Scale (DERS): Factor structure and consistency of a French translation. Swiss Journal of Psychology, 72(1), 5-11. doi:10.1024/1421-0185/a000093

de Campora, G., Giromini, L., Larciprete, G., LiVolsi, V., \& Zavattini, G. C. (2014). The impact of maternal overweight and emotion regulation on early eating behaviors. Eating Behaviors, 15(3), 403409. doi:10.1016/j.eatbeh.2014.04.013

de Campora, G., Larciprete, G., Delogu, A. M., Meldolesi, C., \& Giromini, L. (2016). A longitudinal study on emotional dysregulation and obesity risk: From pregnancy to 3 years of age of the baby. Appetite, 96, 95-101.

Fox, H. C., Axelrod, S. R., Paliwal, P., Sleeper, J., \& Sinha, R. (2007). Difficulties in emotion regulation and impulse control during cocaine abstinence. Drug and Alcohol Dependence, 89, 298-301.

Fox, H. C., Hong, K. A., \& Sinha, R. (2008). Difficulties in emotion regulation and impulse in recently abstinent alcoholics compared with social drinkers. Addictive Behaviors, 33, 388-394.

Freire, T., \& Tavares, D. (2011). Influência da autoestima, da regulação emocional e do gênero no bem-estar subjetivo e psicológico de adolescentes. Revista de Psiquiatria Clínica, 38(5), 184-188. doi:10.1590/ S0101-60832011000500003

Garner, P. W., \& Waajid, B. (2012). Emotion knowledge and self-regulation as predictors of preschoolers' cognitive ability, classroom behavior, and social competence. Journal of Psychoeducational Assessment, 30(4), 330-343. doi:10.1177/0734282912449441

Geisinger, K. F. (2003). Testing and assessment in cross-cultural psychology. In J. R. Graham, J. A. Naglieri, \& I. B. Weiner (Eds.), Handbook of psychology: Assessment psychology (Vol. 10, pp. 95-118). New Jersey: John Wiley \& Sons.

Giromini, L., Brusadelli, E., Di Noto, B., Grasso, R., \& Lang, M. (2015). Measuring psychological mindedness: Validity, reliability, and relationship with psychopathology of an Italian version of the Balanced Index of Psychological Mindedness. Psychoanalytic Psychotherapy. doi:10.1080/02668734.2015.1006666 
Giromini, L., Velotti, P., de Campora, G., Bonalume, L., \& Zavattini, G. C. (2012). Cultural adaptation of the Difficulties in Emotion Regulation Scale: Reliability and validity of an Italian version. Journal of Clinical Psychology, 68, 989-1007.

Glenn, C., \& Klonsky, E. D. (2009). Emotion dysregulation as a core feature of borderline personality disorder. Journal of Personality Disorders, 23, 20-28.

Gratz, K. L. (2007). Targeting emotion dysregulation in the treatment of deliberate self-injury. Journal of Clinical Psychology, 63, 1091-1103.

Gratz, K. L., Bornovalova, M. A., Delany-Brumsey, A., Nick, B., \& Lejuez, C. W. (2007). A laboratory-based study of the relationship between childhood abuse and experiential avoidance among inner-city substance users: The role of emotional nonacceptance. Behavior Therapy, 38(3), 256268.

Gratz, K. L., \& Gunderson, J. G. (2006). Preliminary data on an acceptance-based emotion regulation group intervention for deliberate self-harm among women with borderline personality disorder. Behavior Therapy, 37, 25-35.

Gratz, K. L., Lacroce, D., \& Gunderson, J. G. (2006). Measuring changes in symptoms relevant to borderline personality disorder following short-term treatment across partial hospital and intensive outpatient levels of care. Journal of Psychiatric Practice, 12, 153-159.

Gratz, K. L., \& Roemer, L. (2004). Multidimensional assessment of emotion regulation and dysregulation: Development, factor structure, and initial validation of the Difficulties in Emotion Regulation Scale. Journal of Psychopathology and Behavioral Assessment, 26(1), 41-54. http://doi.org/10.1023/ B:JOBA.0000007455.08539.94

Gratz, K. L., Rosenthal, M. Z., Tull, M. T., Lejuez, C. W., \& Gunderson, J. G. (2006). An experimental investigation of emotion dysregulation in borderline personality disorder. Journal of Abnormal Psychology, $115,850-855$.

Gratz, K. L., Tull, M. T., Baruch, D. E., Bornovalova, M. A., \& Lejuez, C. W. (2008). Factors associated with co-occurring borderline personality disorder among inner-city substance users: The roles of childhood maltreatment, negative affect intensity/reactivity, and emotion dysregulation. Comprehensive Psychiatry, 49, 603-615.

Gross, J. J., \& John, O. P. (2003). Individual differences in two emotion regulation processes: Implications for affect, relationships, and well-being. Journal of Personality and Social Psychology, 85, 348-362.

Gross, J. J., \& Muñoz, R. F. (1995). Emotion regulation and mental health. Clinical Psychology: Science and Practice, 2, 151-164.

Gross, J. J., \& Thompson, R. A. (2007). Emotion regulation: Conceptual foundations. In J. J. Gross (Ed.), Handbook of emotion regulation (pp. 3-24). New York: Guilford Press.

Hervás, G., \& Jódar, R. (2008). Adaptación al castellano de la Escala de Dificultades en la Regulación Emocional. Clínica y Salud, 19(2), 139-156.

Hofstede, G. (1991). Cultures and organizations: Software of the minds. London: McGraw-Hill.

Hu, L. T., \& Bentler, P. M. (1999). Cutoff criteria for fit indexes in covariance structure analysis: Conventional criteria versus new alternatives. Structural Equation Modeling, 6(1), 1-55.

Jesus, A. G., Jr., \& Noronha, A. P. P. (2007). Inteligência emocional e provas de raciocínio: Um estudo correlacional. Psicologia: Reflexão e Crítica, 20(3), 480-489. http://doi.org/10.1590/S010279722007000300016

Keith, T. Z., Caemmerer, J. M., \& Reynolds, M. R. (2016). Comparison of methods for factor extraction for cognitive test-like data: Which overfactor, which underfactor? Intelligence, 54, 34-54.

Klonsky, E. D. (2009) The functions of self-injury in young adults who cut themselves: Clarifying the evidence for affect-regulation. Psychiatry Research, 166, 260-268.

Kossakowska, M. M., Cieścińska, C., Jaszewska, J., \& Placek, W. J. (2010). Control of negative emotions and its implication for illness perception among psoriasis and vitiligo patients. Journal of the European Academy of Dermatology and Venereology, 24(4), 429-433.

Mayer, J. D., Salovey, P., \& Caruso, D. R. (2002). Mayer-Salovey-Caruso Emotional Intelligence Test (MSCEIT) user's manual. Toronto: Multi-Health Systems.

Mayer, J. D., Salovey, P., \& Caruso, D. R. (2012). The validity of the MSCEIT: Additional analyses and evidence. Emotion Review, 4(4), 403-408. doi:10.1177/1754073912445815

McLaughlin, K. A., Mennin, D. S., \& Farach, F. J. (2007). The contributory role of worry in emotion generation and dysregulation in generalized anxiety disorder. Behaviour Research and Therapy, 45, 1735-1752. 
Mennin, D. S., Heimberg, R. G., Turk, C. L., \& Fresco, D. M. (2005). Emotion regulation deficits as a key feature of generalized anxiety disorder: Testing a theoretical model. Behaviour Research and Therapy, $43,1281-1310$.

Michaels, T. M., Horan, W. P., Ginger, E. J., Martinovich, Z., Pinkham, A. E., \& Smith, M. J. (2014). Cognitive empathy contributes to poor social functioning in schizophrenia: Evidence from a new selfreport measure of cognitive and affective empathy. Psychiatry Research, 220(3), 803-810.

Miguel, F. K., \& Primi, R. (2014). Estudo psicométrico do Teste Informatizado de Percepção de Emoções Primárias. Avaliação Psicológica, 13(1), 1-9.

Mitsopoulou, E., Kafetsios, K., Karademas, E., Papastefanakis, E., \& Simos, P.G. (2013). The Greek version of the Difficulties in Emotion Regulation Scale: Testing the factor structure, reliability and validity in an adult community sample. Journal of Psychopathology and Behavioral Assessment, 35, 123-131.

Nunnally, J. C. (1978). Psychometric theory (2nd ed.). New York: McGraw-Hill.

Nyklíček, I., Vingerhoets, A., \& Zeelenberg, M. (2011). Emotion regulation and well-being: A view from different angels. In M. Zeelenberg (Eds), Emotion regulation and well-being (pp. 1-9). New York: Springer.

Primi, R., \& Almeida, L. S. (2000). Estudo de validação da Bateria de Provas de Raciocínio (BPR-5). Psicologia: Teoria e Pesquisa, 16(2), 165-173. doi:10.1590/S0102-37722000000200009

Raubenheimer, J. (2004). An item selection procedure to maximise scale reliability and validity. Journal of Industrial Psychology, 30, 59-64.

Reniers, R. L., Corcoran, R., Drake, R., Shryane, N. M., \& Völlm, B. A. (2011). The QCAE: A Questionnaire of Cognitive and Affective Empathy. Journal of Personality Assessment, 93(1), 84-95. doi:10.1080/00223891.2010.528484

Ruganc1, R. N., \& Gençöz, T. (2010). Psychometric properties of a Turkish version of the difficulties in emotion regulation scale. Journal of Clinical Psychology, 66(4), 442-455.

Salters-Pedneault, K., Roemer, L., Tull, M., Rucker, L., \& Mennin, D. S. (2006). Evidence of broad deficits in emotion regulation associated with chronic worry and generalized anxiety disorder. Cognitive Therapy and Research, 30, 469-480.

Tull, M. T., \& Roemer, L. (2007). Emotion regulation difficulties associated with the experience of uncued panic attacks: Evidence of experiential avoidance, emotional nonacceptance, and decreased emotional clarity. Behavior Therapy, 38, 378-391.

Van de Vijver, F., \& Hambleton, R. K. 1996). Translating tests: Some practical guidelines. European Psychologist, 1, 89-99.

Vikan, A., Dias, M., \& Nordvik, H. (2009). Perceived efficiency and use of strategies for emotion regulation. Psychological Reports, 104, 455-467.

Weisbuch, M., Ambady, N., Slepian, M. L., \& Jimerson, D. C. (2011). Emotion contagion moderates the relationship between emotionally-negative families and abnormal eating behavior. International Journal of Eating Disorders, 44(8), 716-720.

Weiss, L. G., Keith, T. Z., Zhu, J., \& Chen, H. (2013). WAIS-IV and clinical validation of the four- and five-factor interpretative approaches. Journal of Psychoeducational Assessment, 31, 94-113.

Wiethaeuper, D., Abaide Balbinotti, M.A., Pelisoli, C., \& Lopes Barbosa, M.L., (2005). Estudos da consistência interna e fatorial confirmatório da Escala Toronto de Alexitimia-20 (ETA-20). Interamerican Journal of Psychology, 39(2), 221-230.

Willemsen, R., Haentjens, P., Roseeuw, D., \& Vanderlinden, J. (2009). Alexithymia in patients with alopecia areata. Journal of the European Academy of Dermatology and Venereology, 23, 1141-1146. 


\section{Author Query Form}

\begin{tabular}{ll}
\hline Journal & JCLP \\
Article & jclp22404 \\
\hline
\end{tabular}

Dear Author

During the copy-editing of your paper, the following queries arose. Please respond to these by marking up your proofs with the necessary changes/additions. Please write your answers clearly on the query sheet if there is insufficient space on the page proofs. If returning the proof by fax do not write too close to the paper's edge. Please remember that illegible mark-ups may delay publication.

\begin{tabular}{|l|l|l|}
\hline Query No. & Description & Remarks \\
\hline Q1 & $\begin{array}{l}\text { Author: Please confirm that given names (red) and sur- } \\
\text { names/family names (green) have been identified correctly. }\end{array}$ & \\
\hline Q2 & Author: Please provide the complete mailing address. & \\
\hline Q4 & $\begin{array}{l}\text { Author: Should this be Gratz et al? } \\
\text { ticipants were compensated. }\end{array}$ & $\begin{array}{l}\text { Author: A Conclusion heading was added, per this journal's } \\
\text { style. Please provide additional remarks or revise this portion, } \\
\text { which was taken for the previous paragraph. }\end{array}$ \\
\hline Q5 & $\begin{array}{l}\text { Author: This portion seems to be covered already in the pro- } \\
\text { cedure section. Please delete it or add it to the section. }\end{array}$ & \\
\hline Q6 & $\begin{array}{l}\text { Author: Please provide the English translation of the titles } \\
\text { in brackets following the original title, in APA style, as fol- } \\
\text { lows: Janzen, G., \& Hawlik, M. (2005). Orientierung im } \\
\text { Raum: Befunde zu Entscheidungspunkten [Orientation in } \\
\text { space: Findings about decision points]. Zeitschrift für Psy- } \\
\text { chologie, 213(4), 179-186. }\end{array}$ \\
\hline Q7 & \\
\hline
\end{tabular}


Required software to eAnnotate PDFs: Adobe Acrobat Professional or Acrobat Reader (version 8.0 or above). (Note that this document uses screenshots from Acrobat Reader 9 . For screenshots from Acrobat Reader $X$, a separate document is available on the journal e-proofing site.)

The latest version of Acrobat Reader can be downloaded for free at: http://get.adobe.com/reader/

Once you have Acrobat Reader 8, or higher, open on your PC you should see the Commenting Toolbar:

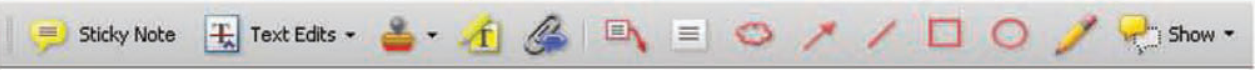

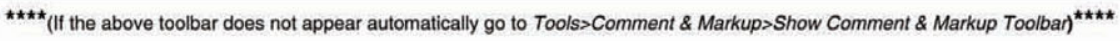

\section{Replacement Text Tool - For replacing text.}

\section{Strikes a line through text and opens up a replacement text box}

\begin{tabular}{|c|c|c|c|}
\hline Es sody Note & 国 Tent Edes: : $3 \cdot 1$ & $\square \equiv \infty>>\square 0$, phow. human mind & human ${ }_{1}$ mind is organized in a modula \\
\hline & IT I Iext Edes Tod & nitive Science Society, Inc. All rights I itably, to the & claim that many aspects \\
\hline & 玉 Beploce Selected Tent & $1551-6709$ online & $\begin{array}{l}622001011: 0554 \text { AM } \\
\text { Optans }\end{array}$ \\
\hline 2 & 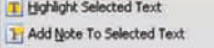 & ntation. Fror & animal \\
\hline 3 & Tithent fertecing & hat orga & reed the mind. From the \\
\hline & $\begin{array}{l}\text { I Underino Selected Tent } \\
\text { I cross out Text for pelobion }\end{array}$ & 1. Highlight a word or sentence nnate at & concarsulated t \\
\hline & & $\begin{array}{l}\text { 2. Select "Replace Selected Text" from the } \\
\text { Text Edits fly down button } \\
\text { 3. Type replacement text in blue box }\end{array}$ & 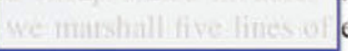 \\
\hline
\end{tabular}

\section{Cross-out Text Tool - For deleting text.} Strikes a red line through selected text.

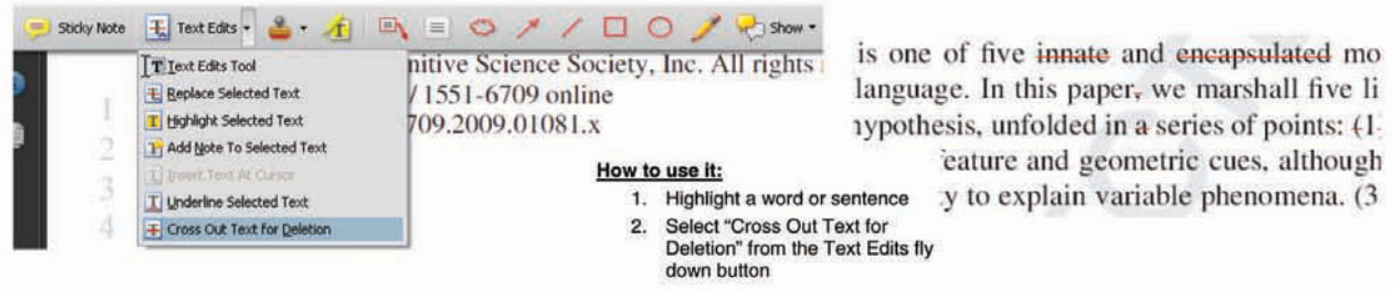

\section{Highlight Tool - For highlighting a selection to be changed to bold or italic. \\ Highlights text in yellow and opens up a text box.}

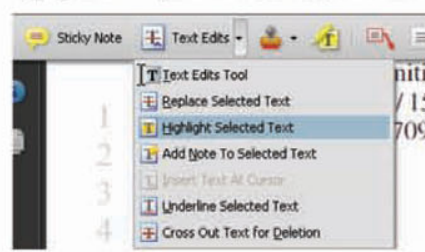
$\equiv 0 \times>\square 0<$ phow iitive Science Society, Inc. All rights I 1551-6709 online $09.2009 .01081 . x$

\section{How to use it:}

1. Highlight desired text

2. Select "Add Note To Selected Text" from the Text Edits fly down button

3. Type a note detailing required change in the yellow box human mind is organized in a mo itably, to the claim that manv asne

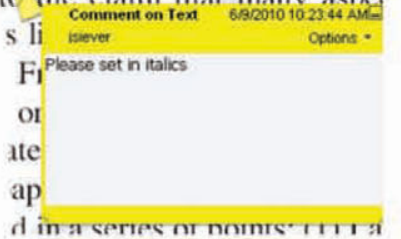

\section{Note Tool - For making notes at specific points in the text} Marks a point on the paper where a note or question needs to be addressed.

Soddy Note $\mathrm{F}_{\mathrm{a}}$ Text Edits -
How to use it:
1. Select the Sticky Note icon from the commenting toolbar
2. Click where the yellow speech bubble symbol needs to appear and a yellow
text box will appear
3. Type comment into the yellow text box

Abstract $\equiv$

It is frequently plaimed that the hut

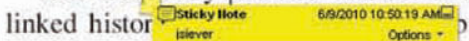
innately spec geometric $\mathrm{m}$ module wou! the reorienta mented by u. ..................................... 


\section{Drawing Markup Tools - For circling parts of figures or spaces that require changes} These tools allow you to draw circles, lines and comment on these marks.

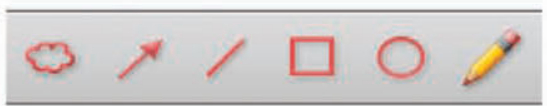

How to use it:

1. Click on one of shape icons in the Commenting Toolbar

2. Draw the selected shape with the cursor

3. Once finished, move the cursor over the shape until an arrowhead appears and double click

4. Type the details of the required change in the red box

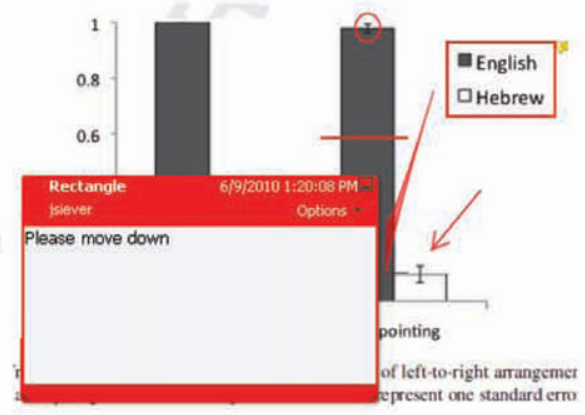

6. Attach File Tool - For inserting large amounts of text or replacement figures as a files. Inserts symbol and speech bubble where a file has been inserted.

matter to be changed How to use it: $\begin{array}{ll}\text { matter to be clarnged } & \text { 1. Right click on the Commenting Toolbar }\end{array}$

matter to be changed 3. Click on paperclip icon that appears in the

natter to be changed

4. Click where you want to insert the

attachment

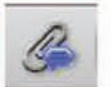

5. Select the saved file from your PC or

network

6. Select type of icon to appear (paperclip, graph, attachment or tag) and close

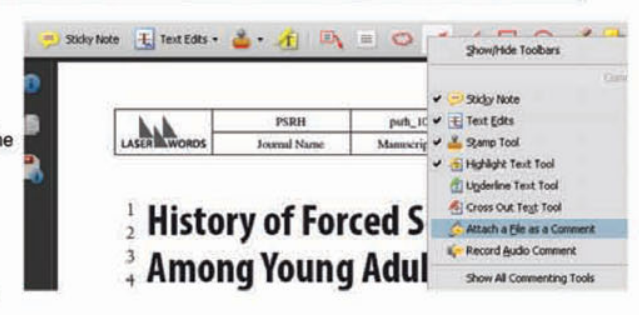

\section{Approved Tool (Stamp) — For approving a proof if no corrections are required.}

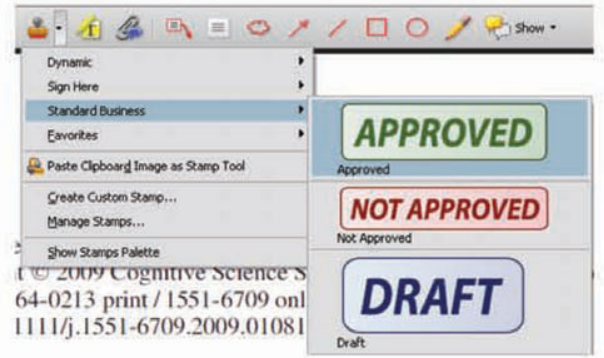

How to use it:

1. Click on the Stamp Tool in the toolbar

2. Select the Approved rubber stamp from the 'standard business' selection

3. Click on the text where you want to rubber stamp to appear (usually first page)

Help

For further information on how to annotate proofs click on the Help button to activate a list of instructions:

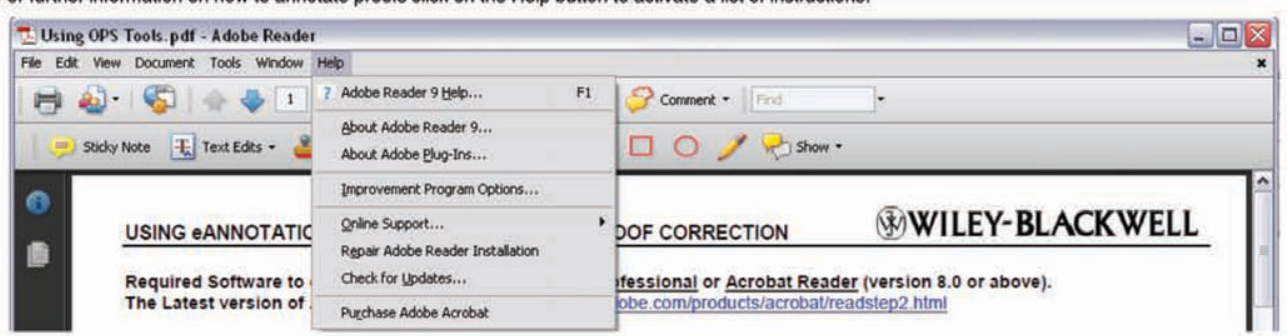

